\title{
Interseçāo de subjetividades: a presença indígena na escrita afetada dos jesuítas
}

\author{
Intersection of subjectivities: the indigenous presence in the \\ affected writing of the Jesuits
}

\author{
Guilherme Galhegos Felippe \& Carlos Daniel Paz \\ https://orcid.org/0000-0003-4008-4926 iD \\ https://orcid.org/0000-0002-2297-3458 iD
}

\section{RESUMO}

A produção escrita desenvolvida pelos membros da Companhia de Jesus ao longo da experiência reducional na América espanhola adquiriu novo fôlego de análise quando os estudiosos compreenderam que esses registros compunham a interseção entre as subjetividades dos seus autores e as demandas formais que a hierarquia da Ordem impunha aos missionários. Por isso, são frequentes os registros que contêm descrições detalhadas de cerimônias, práticas xamânicas, relatos sobre a mitologia e de outros aspectos relativos ao conhecimento prático indígena, que se situam entre a obrigação de registrar e o interesse do jesuíta. Neste artigo, pretendemos demonstrar que a presença, a atuação e os saberes dos índios também provocaram perturbações nesses registros, gerando o que chamamos de uma escrita afetada: a expressão discreta, já que não é proveniente de um esforço de convencimento por parte do narrador, do resultado da ponderação do missionário ou da influência direta ou indireta que os nativos exerceram a partir do contato e convívio reducional.

\section{PALAVRAS-CHAVE}

Missões do Chaco; Escrita jesuítica; Saberes indígenas

\section{ABSTRACT}

The written production developed by the members of the Company of Jesus during the reduction experience in Spanish America acquired a new impulse of analysis when the researchers perceived that these records were composed of the intersection between the subjectivities of the authors and the formal demands that the hierarchy of the Order imposed on the missionaries. Because of this, records containing detailed descriptions of various ceremonies, shamanic practices and stories about mythology are frequent, as well as other aspects related to indigenous practical knowledge, which are placed between the obligation to record native behavior and the interest of the Jesuit. In this article we intend to demonstrate that the presence and performance of native knowledge also caused disturbances on these records generating what we call an affected writing. An intimate expression that does not come from the effort of convincing on the part of the narrator, but that is the result of the missionary's weighting and of the direct or indirect influence that the natives exerted through contact and reductionist coexistence.

\section{KEYWORDS}

Reductions of Chaco; Jesuit writing; Native knowledge 


\section{İntroduçāo}

Naturalmente, eles existem enquanto eu olho para eles, mas também eu existo enquanto alguém, não sei quem, olha para mim. (Sigismund Krzyzanowski, "Dentro da pupila")

Es, sin duda alguna, mil veces preferible que sea uno y no el mundo lo que vacila (Juan José Saer, "El Entenado")

A atuação catequética dos missionários da Companhia de Jesus na região do Gran Chaco, na época colonial, foi marcada por sucessivas tentativas de aproximação com os grupos indígenas, que nem sempre corresponderam às expectativas dos padres e, menos ainda, dos colonos que ali montaram residência. O espaço do Chaco - região que abarca o atual território da Argentina, Paraguai, Bolívia e Mato Grosso do Sul, no Brasil, estendendo-se do limite andino até o Rio da Prata -, com sua vasta e ampla geografia, bem como pela diversidade de grupos étnicos que o povoavam, chamou a atenção dos missionários desde muito cedo. Já no começo do século XVII, há notícias, registradas por distintos sacerdotes jesuítas, dos ambientes plenamente interconectados entre si, ainda que claramente diferenciados uns dos outros, bem como dos distintos grupos nativos que ali residiam. Grupos parentais que eram descritos pelos sacerdotes, apelando aos valores e práticas que, para além de oporem-se à civitas cristã (CARGNEL; PAZ 2012), evidenciavam o ousado e perigoso trabalho apostólico. Assim, o prolongado contato entre índios e brancos na região, iniciado de fato com a criação da Governação de Tucumã, em 1563, que ficaria sob jurisdição da Audiência de Charcas, gerou as mais variadas formas de convívio e conflito, submetidas, sempre, aos diferentes interesses sustentados por cada lado.

A dinâmica social indígena presente nas fronteiras orientais e ocidentais do Chaco - o Chaco de Santa Fe e o Chaco de Salta -, ainda que apresente semelhanças em relação a processos 
sociais ocorridos no seio das comunidades nativas, mesmo com a expansão das fronteiras hispano-crioulas, possuía diferenças substanciais que devem ser descritas, explicadas e analisadas. Entre as diferenças mais significativas, encontra-se o ciclo de guerras entre grupos nativos do Chaco oriental, exemplificado pelos casos dos índios Abipone e os Mocovi - que foram os que concentraram maior atenção daquela escrita considerada etnológica, tendo como maiores expoentes as crônicas dos padres jesuítas Martín Dobrizhoffer (1784) e Florián Paucke (1767) -, cujos enfrentamentos foram muito mais violentos do que os descritos entre grupos indígenas do Chaco saltenho. ${ }^{1}$

A fundação de cidades, fortificações, estâncias e reduções no entorno do Chaco efetivou a presença colonial na região, sem, com isso, garantir uma boa convivência com os indígenas: ainda que tenha ocorrido uma aproximação pacífica e colaboracionista entre as partes, em que indivíduos ou grupos indígenas não apenas aceitaram a presença colonial no território, como também usufruíram dos expedientes e fizeram parte dos meios instalados pela administração civil e religiosa, os relatos da época não deixam dúvida de que a situação foi mais complexa do que gostariam os agentes coloniais. Neste processo de construção das relações com os agentes e dispositivos de poder coloniais, sobretudo ao longo do século XVIII e durante o processo de fundação das principais reduções instaladas no Chaco santafesino, é possível notar processos de complexificação social que estavam acontecendo no seio das chefias indígenas e que podem explicar por que as guerras intra e interétnica adquiriram a dimensão que evidencia o corpo documental disponível e largamente analisado (cf. PAZ 2007; 2009). Assaltos, furtos e latrocínios - além das práticas tradicionais como poligamia, antropofagia, bebedeiras e as curas xamânicas - foram tópicos reiteradamente relatados por aqueles que, de forma direta ou indireta, conviveram com os índios e pretenderam registrar suas impressões.

Ainda que tenhamos que questionar e criticar esses registros como percepções (quase sempre) binárias de observadores 
que projetavam suas concepções a respeito da "Humanidade" a fim de tornar o selvagem "'pensável', antes que realizável" (AGNOLIN 2007, p. 477), não se deve ignorar o fato de que tais relatos são a consequência escrita da perturbação que a presença e a atuação dos índios exerceram sobre quem registrou. A afetação, portanto, é uma qualidade construída através do encontro traumático e da capacidade de resiliência do sujeito, colocando em evidência pelo menos duas maneiras de conceber a ordenação e o funcionamento do mundo: a de quem afeta e a de quem é afetado. A afetação, ou a condição afetada, pode ser analisada através do discurso que o sujeito elabora a posteriori de estar sujeito à tensão dos sistemas normativos com os quais interagiu. Dessa forma, a escrita, na qual a experiência vivida é narrada, é apresentada como um meio privilegiado para investigar essas tensões, que tem sua origem, ao menos como ponto metodológico inicial para construir uma análise como propomos aqui, na confrontação direta no espaço do Chaco com aqueles indígenas que aparecem descritos de modo ideal na escrita consultada pelos noviços jesuítas durante sua formação nos Colégios e Universidades. Essa primeira ruptura, produto do encontro com um sujeito ontologicamente ciente de si e com uma capacidade de agência notável, é a que anima os escritos do século XVIII, em que, para os sacerdotes, o encontro com os nativos parece ser sempre o primeiro, ao passo que, para os indígenas, não se constitui como tal. Concorda-se, então, que aqueles escritos tendem a revelar muito mais sobre as noções, conceitos, ideias, desejos e intenções de quem escreveu do que de quem foi descrito; mas aquele que relata também o faz, em algum grau e em alguns momentos, por causa das contingências externas que lhe afetam: este não é necessariamente o motivo que levou os jesuítas a escrever - ainda mais se levarmos em conta que registrar suas experiências, a partir de rigorosa formalidade, e fazê-las circular entre os demais membros era uma das prerrogativas da Ordem (LONDOÑO 2002) -, mas muito do que escreveram reflete sua postura a respeito do que observavam e tentavam classificar ou do seu 
estranhamento frente ao que Ihes era inexplicável - ou inclassificável - para o seu sistema de códigos culturais e protocolos sociais.

Entre o que foi observado, ouvido ou experienciado pelos jesuítas e o que virou registro em suas cartas, diários, crônicas, tratados ou memórias encontra-se uma infinidade de informações que foram, em parte, ignoradas, analisadas, criticadas ou decodificadas antes de tornarem-se relato. Estes registros eram produzidos com a finalidade de responder a uma demanda institucional, que determinava como os membros da Companhia deveriam escrever os seus relatos a partir de normas e preceitos rigorosos que, como "uma autoridade que, externa à escrita mas insinuada nela, desenha os marcos do possível" (MARTÍNEZ 2001, p. 76). ${ }^{2}$

A produção de obras impressas realizadas pelos membros da Companhia de Jesus durante a sua atuação missionária no período colonial americano é ampla e abrange um número notável de temas. No caso do Chaco, o conjunto de obras é significativamente menor, bem como o número de obras que foram publicadas após a expulsão pelos padres jesuítas que lá cumpriram suas tarefas evangélicas. Assim, as obras de Martín Dobrizhoffer (1784), José Jolís (1789) e Florián Paucke (1767), além de Pedro Lozano (1733), são escritos indispensáveis a qualquer estudo sobre o Chaco. A partir da consulta dessas obras, é possível compor uma análise profunda dos eventos ocorridos durante boa parte do século XVIII, além de representarem uma fonte rica a ser explorada na busca de chaves analíticas que permitam elucidar vários aspectos da vida dos grupos indígenas e das relações que foram estabelecidas.

Deste modo, o objetivo principal deste artigo é analisar, nas principais obras impressas pelos membros da Companhia de Jesus, como se manifestou aquela escrita afetada, tanto no que pode indicar sobre um momento particular do processo reducional; naquilo que reflete sobre alguns aspectos da vida cotidiana dos indígenas; ou como essa escrita afetada representa momentos de inflexão do ser jesuíta, que permitem propor em 
que medida o cruzamento e a tensão das perspectivas em jogo (do missionário e do indígena) são úteis para complexificar as análises sobre os modos em que se registrou a construção de relações sociais entre uns e outros.

Nossa proposta de uma escrita afetada é baseada em uma análise crítica de uma condição de enunciação retórica persistente em boa parte da documentação consultada para a elaboração do conceito em discussão. O corpo documental inaciano se reproduz assim mesmo em mais de uma ocasião quase sem críticas. Algumas das afirmações produzidas por certos membros da Companhia de Jesus são repetidas com uma clara intencionalidade retórica e pedagógica. Diferentes membros da Ordem, em mais de uma ocasião, e ao longo do tempo, vivenciaram adversidades, expondo algumas características culturais nativas que os colocaram contra sua capacidade de acomodação. Afirmações que não foram imediatamente questionadas pelos autores jesuítas e que, em sua época, registraram em suas obras temas recorrentes sobre a vida dos nativos. Portanto, o que torna singular as etnografias culturais escritas pelos diferentes missionários para a análise da escrita afetada é a repetição cíclica das ações dos nativos inconstantes que desafiaram as reduções com uma constância notável. Dentro desse ciclo de menções sobre o caráter nativo, detectamos a afetação de quem escreve.

\section{A escrita jesuítica: uma subjetividade desvanecida?}

A escrita, para os jesuítas, foi uma ferramenta fundamental não só em sua atuação missionária na forma de apreensão e troca de experiências entre os membros da Ordem, como também um exercício voltado à atividade intelectual, em que muito do exótico, do desconhecido e do incompreendido foi analisado, pensado, assimilado - com alguns limites - e logo, então, transferido para o papel na forma de conhecimento e saberes acumulados. Portanto, o papel desempenhado pelos jesuítas não se restringiu à pregação e evangelização dos nativos, nem somente à reflexão teórica sobre a natureza. Isso 
quer dizer que tanto a atuação missionária, como a dedicação à produção de conhecimento eram realizadas concomitantemente pelos membros da Companhia, que se encontravam na situação solitária de evangelização nas reduções. A experiência, certamente única em suas vidas, providenciou o cenário natural mais apropriado para suas elucubrações, além do período de contato e convívio com os nativos, influência determinante no processo pelo qual os missionários tiveram que passar durante a sua adaptação e estabelecimento de residência em missão.

Centralizada por Roma, a correspondência funcionava como um instrumento para "evitar a excessiva dispersão dos membros da Companhia, assegurando o 'nosso modo de proceder', que denotava a tão desejada uniformidade entre os membros da Companhia" (EGIDO et al. 2004, p. 39). Estabelecia-se, por meio de tal controle, uma aproximação entre os missionários espalhados por territórios distantes, diminuindo a solidão experimentada nos espaços periféricos que contrastavam com os lugares de origem de cada sacerdote. Ao mesmo tempo, a escrita convertia este senso de união em uma "polícia do trabalho", pois se fazia presente nos "questionamentos que se fazem à sua escrita, ao censurá-la ou ao não editar seus livros - já que o poder da censura e o controle das paixões que a escrita devia exercer estavam fixados pela comunidade que formava a instituição" (CARGNEL 2015, p. 39-40). A uniformidade pretendida pela Ordem alcançava sua efetividade, na medida em que reforçava o controle hierárquico por meio da comunicação constante entre seus membros.

Mas era justamente nestas correspondências que os jesuítas encontravam espaço para também colocarem suas impressões e considerações pessoais. Aqueles que, por meio do voto de obediência, ingressaram na Companhia de Jesus, "abriram mão de parte de sua individualidade, mas, ao mesmo tempo, esta nunca foi anulada a ponto de que seus gostos e talentos, seus temperamentos e formas de agir, não tivessem imprimido marcas no que fizeram" (FLECK et al. 2014, p. 18). Dito de outra forma, mesmo que uma parte dos registros fossem formalidades 
predefinidas pelos rigorismos exigidos por uma Ordem religiosa que depositava grande valor na comunicação escrita (LONDOÑO 2002), muito do que foi registrado escapava, por assim dizer, do protocolo determinado pelas normas e acaba informando mais do que pretendia - sem, com isso, necessariamente fugir do objetivo inicial de registrar a experiência catequética, manter os demais membros da Ordem informados e dar satisfações aos superiores. Ainda que houvesse uma demanda institucional que levava os missionários a compartilharem suas experiências por meio de uma formalidade estrita, era na prática da escrita que podiam elaborar os seus pontos de vista pessoais a respeito do que experenciavam.

É certo que, no contexto missionário da Companhia de Jesus, a "escrita estava a serviço da conversão" (NEUMANN 2015 , p. 49) e, por isso, a prioridade era utilizar-se dela como instrumento de apologia tanto em defesa à conversão dos índios, como à permanência dos jesuítas no trabalho missionário. Assim demonstrou Maria Cristina dos Santos (2016), ao analisar um relato produzido em 1636, em que o padre José Oregio, autor do registro, acusa o índio Erovocá de ter comido a carne de seus parentes e pessoas próximas. Segundo a historiadora, apesar de o autor do relato alçar o indígena como protagonista de seu registro como forma de reunir nele toda a barbárie com a qual os missionários tinham que conviver, este é mais um documento histórico em que a narrativa missionária tem como objetivo colocar a atuação catequética como protagonista, servindo como propaganda da Ordem, ao ressaltar a importância dos jesuítas como os únicos que "garantiam a solução para um problema que não dependia das decisões da Coroa, nem de outras decisões locais" (2016, p. 1111).

A correspondência, em intensa circulação não apenas entre os membros da Ordem, não se restringia apenas a assuntos da fé: buscando não "se fechar nos claustros", os jesuítas pareciam determinados a ocupar "tanto o espaço social como o religioso" - o que, inclusive, levou os críticos da Companhia a 
não reconhecerem os jesuítas nem como parte do clero comum, nem como parte do clero secular (WRIGHT 2006, p. 55-56).

A Companhia de Jesus exigia um certo rigor intelectual de seus integrantes (MILLONES FIGUEROA; LEDEZMA 2005, p. 9), privilegiando as faculdades da oratória e da comunicação escrita, além de "formar sacerdotes de salientes capacidades intelectuais" (JUSTO 2011, p. 156) nas áreas da filosofia, teologia, história e ciências naturais. Assim, os jesuítas que eram aceitos pela Ordem para atuarem entre os neófitos na América acabavam dividindo-se, na medida do possível, entre a atuação evangélica junto aos índios e seus interesses intelectuais, colocando-se na "condição de sujeitos que transitaram entre a prática catequética e as atividades mais estritamente relacionadas ao cumprimento do seu apostolado e uma série de outras ocupações, tais como as ligadas ao ensino, à filosofia, à literatura e às ciências" (FLECK et al. 2014, p. 13). Ainda que em suas cartas escritas aos superiores devessem cumprir com obrigações e urgências relativas ao trabalho de evangelização, sabemos que, no dia a dia, os jesuítas mantinham-se atuantes em suas áreas de formação, como fica evidente nos esforços do padre Antônio Sepp, compositor que introduziu o ensino de música entre os índios reduzidos (LARA 2015), ou o padre Pedro Lozano, cujas obras dedicadas a registrar o passado da Província Jesuítica do Paraguai, conferiram-lhe o título de historiador da Companhia de Jesus (CARGNEL 2015). Em outras palavras, os seus saberes e as suas produções intelectuais estiveram intimamente relacionados às práticas da conversão (JUSTO 2011, p. 155).

Entende-se, portanto, a complexidade que envolvia a escrita jesuítica, não apenas no que tocava ao controle da circulação da correspondência e à formalidade exigida pelos superiores, mas também relativo às particularidades da formação intelectual e psicológica de cada missionário. Cada jesuíta, antes de ser enviado em missão, tinha seus dados pessoais e perfil psicológico e comportamental listados nos Catálogos Trienais desenvolvidos pelos superiores da Companhia em Roma, 
usados fundamentalmente para "distribuir adequadamente os membros da Ordem para lugares e missões, levando em conta sua compleição própria e outras características" e, assim, melhor adequá-los ao empreendimento missionário (PANAZZOLO; MASSIMI 2015, p. 25).

Os esforços de adequar sua narrativa às ordens impostas a partir do que e como se devia escrever possuía uma vinculação com o problema do discernimento - peça chave na formação e na atuação do jesuíta. Nesse aspecto, que ajuda a identificar ainda mais a afetação refletida na escrita, é necessário compreender aquilo que se conhece como a "eleição do segundo tempo" momento em que o futuro sacerdote experimenta um conjunto de emoções e inquietações que o praticante, aquele que realiza dos Exercícios Espirituais, não pode controlar (JUANES 1980, p. 76). Momento de dúvida, mas de afirmação, em que o futuro sacerdote confirma sua eleição vocacional. Essa vontade incontrolável pode ser concebida como a mesma a que é exposto o sacerdote uma vez instalado no seio da comunidade em que tentará levar o evangelho e sua prática aculturadora.

Nesta situação, encontra-se exposto a diversos estados da alma e, muitas vezes, também a erros, visto que o homem pode ser movido não somente pelo Espírito, mas frequentemente enganado pelo que aparenta ser bom e correto. [...]. Portanto, a dificuldade em discernir os diferentes espíritos começa pelo seu próprio desempenho, da conivência que, mesmo inconsciente, nossas afeições desordenadas podem oferecer (JUANES 1980, p. 77-78).

Esta afeição desordenada é a que acontece em diversos momentos da vida cotidiana dos padres nas respectivas reduções às quais foram destinados. Ali, a densidade - no sentido geertziano - da realidade social parece exercer ânimos e vontades, fazendo-se perceptível em uma escrita que tenta ordenar de modo lógico ações próprias da vida nativa, que confrontam e parecem desafiar a lógica ocidental na qual o jesuíta está inserido. Desse modo, os esforços de adequação 
são os que, em certa medida, impulsionam a materialização daquela escrita afetada: um momento em que o padre, por mais que tente discernir sobre os atos nativos que mobilizam seus medos, angústias e dúvidas sobre diversas questões, tem a sua posição de sujeito- observador reforçada, deixando marcas do seu Eu-mesmo na escrita.

Partimos da noção proposta por José Antonio Kelly (2001) de "personitude fractal", na qual, segundo o autor, a pessoa é uma conjunção de escalas de acordo com sua posição e atuação nas relações internas e externas. Esse "divíduo" dispõe-se simultaneamente como sujeito-Eu/objeto-Outro: pessoas "não são nem objeto nem sujeito, mas ambos: o ponto de encontro de um Eu reflexivo e da perspectiva do Outro". A escala é mais complexa, pois envolve tanto esta relação com outro-alguém, como divisões internas à própria pessoa: "a pessoa-como-grupo é uma versão em escala ampliada da pessoa-como-indivíduo e uma versão duas vezes ampliada da pessoa-como-parte" (KELLY 2001, p. 100 e 102). Jesuítas e indígenas ocuparam, na convivência direta, estas posições dualistas um para o outro, não havendo, no nível da relação, uma predominância no contexto - exceto, obviamente, pelo fato de os missionários registrarem a partir de sua posição de sujeitos sobre os indígenas-Outro. Na situação de convívio reducional, podemos imaginar que os jesuítas se sentiam observados e analisados a todo momento pelos índios e, nessa oscilação entre ser sujeito de ação e objeto de observação, os missionários deixavam manifestar sua dualidade.

Por isso, o discurso escrito produzido pelos membros da Companhia de Jesus deve ser tomado como uma narrativa em camadas, que resultou das diferenças entre a ordem do discurso e a ordem factual almejada (MORALES 2011, p. 33) - entre o que deveria ser registrado e aquilo que fazia parte das impressões pessoais do autor, motivadas a partir de suas experiências concretas, sensoriais e filosóficas frente ao momento que estava vivendo e com quem estava convivendo. 
O que assentou na memória do jesuíta e tornou-se consciência sobre a realidade a qual estava inserido não estava apenas condicionado à sua formação religiosa e intelectual e aos expedientes protocolares da Ordem, mas também à sua interpretação do entendimento que fez sobre o convívio com os índios. A escrita jesuíta, sob tal análise, passa a ser o que Guillermo Wilde descreve como uma prática com muitos sentidos possíveis decorrentes do convívio, em que, para os jesuítas, a experiência missionária não se apresentava como um problema relativo aos dilemas da conversão, mas sim à conversão como dilema $(2011$, p. 20$)$ : a presença do indígena que deveria ser convertido afetava tanto a atuação catequética do jesuíta, como a sua forma de relatar o que observava ou ficava sabendo a respeito dos nativos. Esta afetação, no sentido que queremos analisar, tem menos a ver com implicações morais do que uma influência perceptiva que atinge os relatos produzidos pelos jesuítas, sob a qual o convívio direto com os nativos repercutiu, na escrita, na forma de interação - ou, como sintetizou Carlo Ginzburg, "o confronto prolongado de culturas diferentes, pressupõe uma perspectiva dialógica" (2007, p. 285-286).

Foi inevitável que os jesuítas, distantes cada vez mais dos centros de influência da Ordem, sentissem a obediência perder sua "imperfeição militar": a tomada de decisões pessoais ganhava maior espaço nos registros, permitindo que o tribunal da consciência operasse com mais autonomia (MORALES 2011, p. 35). Parte-se do que Ivonne Del Valle (2009) propõe em relação ao "incômodo físico e mental" que o impacto com o ambiente e os indígenas produziu na escrita dos missionários, identificado pela autora como o encontro das tensões entre a epistemologia ilustrada e imperial e a vida indígena nas fronteiras (2009, p. 10-14).

É neste espaço narrativo, em que a obrigação de escrever aos superiores era superada pelas impressões e interpretações pessoais, que traços de interações "nos informam sobre os dois atores presentes, índios e missionários, suas estratégias 
de reconhecimento mútuo, de apropriação e de alienação" (CASTELNAU-L'ESTOILE 2013, p. 82). É desta forma que os registros produzidos pelos missionários em atuação junto aos índios do Chaco revelam esta "dimensão dialógica" (GINZBURG 2007, p. 290) do discurso jesuítico, construído pelo ímpeto pessoal de homens movidos pelos interesses na religião, no intelecto e no saber, mas também provocado pelo contato direto com os nativos nas missões. Alterações que permitem entrar nos imaginários da linguagem - aqueles transmitidos e mesmo os reprimidos - e, a partir dos seus vestígios, pensar como atua a "inconsciência do inconsciente" (BARTHES 1978, p. 47), possível de ser questionada por meio da escrita afetada.

\section{A escrita afetada}

Os jesuítas, estes "homens de ação", encontraram na escrita uma forma de seguir "intervindo na realidade", mas sem conseguir se livrarem da "obsessão pela América" (OLLERO et al. 1989, p. 86) - e, para que essa dominação não se apoderasse deles e os transformasse no que não desejavam ser (aqueles homens rudes e bárbaros que eram os índios), recorria-se constantemente à escrita, tal como indicavam as Instrucciones do jesuíta Juan Alfonso de Polanco, de 1547. Secretário de Inácio de Loyola, Polanco definiu as Reglas acerca del Escribir para los de la Compañía, em que foi claramente estabelecido o tom, o conteúdo e a periodicidade que deveriam ter as cartas escritas desde as Missões, por mais remotas que fossem, para logo serem enviadas à Roma, passando primeiro pela supervisão daqueles jesuítas que possuíam funções administrativas como os padres Provinciais. ${ }^{3}$ Assim, controlavam-se as informações registradas nas cartas, para que pudessem ser remitidas sem temor que fossem lidas por inimigos da Companhia. Por isso, a escrita jesuítica era considerada uma escrita para mostrar, sendo possível, portanto, encontrarmos, nos textos produzidos pelos padres, menções que refletem como se encontravam os seus estados de ânimo. 
Dentro desse conjunto de menções, um aspecto aparece como notório e indiciário para poder rastrear e analisar de forma mais profunda os efeitos daquela afetação que a vida reducional em latitudes tão distantes gerava sobre os missionários.

A conversación, como processo destinado à conversão dos nativos ao cristianismo (MÖRNER 1999, p. 8), colocava o missionário recém-chegado frente a um acúmulo de problemas de convivência com os nativos e com o espaço que circundava a redução - que se manifestava rapidamente com a confrontação ontológica de regimes de corporalidade. O corpo do padre é o primeiro a mostrar os sinais resultantes do que foi habitar aqueles novos espaços, e não faltam descrições sobre como algumas práticas indígenas de sociabilidade, sexualidade, tratamento dos humores corporais, afetividade, bem como a comensalidade, repugnavam os jesuítas. Por isso, é importante ponderar que mesmo o corpo do sacerdote, e por extensão, o corpo dos nativos, é onde, em boa medida, origina-se aquela afetação primeira dos sentidos, que logo é registrada pela escrita inaciana desde uma posição na qual o jesuíta mantinha seu ser não incorporando - ou não tolerando - práticas corporais ou sociais do mundo indígena.

A esse respeito, e a modo de exemplo, encontramos a menção de Joaquín Camaño em sua "Noticia del Gran Chaco", quando fez alusão à prática da circuncisão feminina entre alguns grupos amazônicos como os Pano, para, então, discutir se isso ocorria entre os grupos chaquenhos. Em uma carta enviada a Lorenzo Hervás, de primeiro de maio de 1783, perguntava-se como é que um companheiro de Ordem teria conhecido aquela prática, acrescentando incisivamente: "parecia-me muito, muito indecente a curiosidade do missionário" (In: FURLONG 1955, p. 144). Apreciação que reforça a reticência jesuítica em aceitar perspectivas e práticas corporais próprias da indianidade. "Adquirir uma outra perspectiva implica adotar novos hábitos corporais" (VILAÇA 2008, p. 196) e, portanto, afastar-se de alguns preceitos que promoviam; questão que atingiu alguns 
jesuítas nas fronteiras do extremo norte do território colonial espanhol (VALLE 2009).

Estes costumes e práticas, qualificados em sua grande maioria como vícios de gente sem pudor ou moral e ausente dos princípios doutrinários da Igreja cristã, são o que aparecem recorrentemente descritos nos relatos inacianos. Ainda que boa parte da descrição das práticas nativas com relação à corporalidade apresente uma funcionalidade heurística na narrativa jesuítica, como os efeitos de ressaltar e justificar a expertise do seu trabalho nas reduções, não podemos esquecer que também indica um forte repúdio por parte dos jesuítas do mundo e das práticas dos indígenas. Não só a recusa em aceitar vínculos com mulheres distanciava-os daqueles sobre os quais queriam catequisar, como quase todas as práticas de socialidade e sociabilidade indígena pareciam desvirtuadas para os jesuítas, os quais, em seu afã de expor suas qualidades como um templo inabalável, recorriam à escrita como mostra constante daquilo que os separava dos nativos. Desse modo, a prática da escrita impede que o jesuíta se acomode à situação posta e, ao escrever, indique a afetação que aquele contexto e convívio resultaram em si. Mesmo que nem sempre a escrita tenha deixado transparecer as perturbações do seu autor, conhecemos casos de jesuítas acusados pela própria Companhia como sujeitos abalados que se deixaram desvirtuar (VALLE 2009; NEUMANN 2016).

A escrita, portanto, passa a ser a expressão de uma experiência vivida e incorporada por homens cujas vidas foram dedicadas à doutrinação e que tiveram, na prática da relação com o outro, suas impressões e noções sobre o mundo alteradas. O missionário, que em seu intento de compartimentar o seu Outro radical, o nativo, deixa-se absorver por seu Eu-mesmo, dando passo à conformação/elaboração de um discurso que utiliza a escrita como instrumento para domesticar o indígena, assim como para amenizar o medo, pavor e angústias que lhe infligem desde os instantes iniciais da empresa reducional. 
A escrita, fosse ela cotidiana ou o resultado das obras produzidas por alguns jesuítas que insistiram em registrar seu conhecimento no exílio após a expulsão, foi o lugar (e também o momento) que o missionário-narrador encontrou para imprimir essa bagagem adquirida e sobre a qual certamente ponderou muito - sendo inevitável que a alteridade também fosse depositada em seu registro. Porém, o Outro nem sempre é apenas descrito ou mencionado por aquele que escreve: algumas vezes parece interagir na escrita, mas não da forma como Michel de Certeau sugeriu que ocorre, eventualmente, quando há lapsos no discurso, como dejetos da escrita que ela "produz ao triunfar, mas que não visava a produzir" (1975, p. 227); tampouco o que François Hartog aponta como aquilo que, nas "descrições estranhas", aparentemente desprovidas de marcas de enunciação, deixam "espaço para enunciação, sob a forma de vestígios" (1980, p. 266).

Ainda que essas sejam formas possíveis de se encontrar o Outro nos registros oficiais, o que pretendemos aqui é salientar os momentos em que o jesuíta conscientemente produz seu registro, incorporando as alterações que sofreu em decorrência do contato direto com os índios. Nem o "desvio" que falou a mais do que pretendia o narrador (CERTEAU 1975, p. 85), nem as técnicas empregadas para "transmitir uma certa carga de alteridade" ao remetente (HARTOG 1980, p. 268): a escrita afetada é o resultado da ponderação; é a expressão discreta, já que não é proveniente de um esforço de convencimento por parte do narrador, do vínculo que os jesuítas e os índios estabeleceram durante o período de convívio reducional. A escrita afetada é a expressão materializada por meio da narrativa de uma pessoa que se encontra em um mundo de relações que, mesmo pressentidas ou identificadas em distintos graus, incide discretamente sobre ela, expondo suas percepções sem reacomodação alguma.

Os fragmentos em que se podem perceber perturbações na escrita são raros no conjunto de registros jesuíticos, pois são a evidência subliminal da incomum situação em que o missionário 
foi afetado pelo indígena, não em um sentido moral ou devido a um esforço de empatia - como se o missionário tivesse experimentado colocar-se no lugar do outro -, mas sim como o resultado de um estar presente, que gerou o alargamento do "estoque de imagens" sobre o mundo, ainda que o observador que escreve não se instrua sobre aquele dos indígenas (cf. FAVRET-SAADA 1990, p. 158-159).

Esse tipo de perturbação na escrita jesuítica pode ser exemplificado com um caso ocorrido com o padre jesuíta Florián Paucke durante sua experiência reducional junto aos índios Mocovi. O jesuíta narra que, certa vez, quando viu os índios preparando uma carne para assá-la, alertou-lhes para o fato de que ela estava suja de terra e que deveriam, portanto, lavála com água. Não dando muita importância para o que o padre sugeria, afirmaram-lhe que "o fogo consumia tudo". Frente às insistências de Paucke, um dos índios colocou o "pedaço de carne sujo e emporcalhado" junto à fogueira, foi até uma poça barrenta, encheu a boca e "cuspiu a água sobre a carne, passou a mão algumas vezes por cima e por baixo da carne e colocou-a de volta no fogo". Apesar do tom recriminador do relato, o jesuíta conclui assumindo que, em outras oportunidades, "quando comi semelhantes assados, não senti qualquer asco ou repulsa, saboreando-os com a ideia de que $o$ fogo absorve tudo" (PAUCKE 1767, p. 292-293, grifos nossos).

Ao aderir à forma como os índios preparavam seu alimento, o jesuíta se permitiu entender que havia uma prática usual na maneira de prepará-lo e, antes disso, uma lógica prática: ter percebido que os indígenas agiam a partir de experiências e saberes próprios, ainda que não os tenha compreendido ou aceitado de todo, deve ter sido o gatilho que lhe afetou e transmitiu-se, como propagação, no registro. E é bastante significativo que o ponto de interação irradiado para a escrita do jesuíta tenha sido um aspecto relacionado às práticas do cotidiano dos índios, cujos conhecimentos e saberes, em certa medida, tiveram lugar nos estudos realizados pelos missionários. 
Assim ocorreu quando alguns missionários se interessaram em descrever os aspectos naturais das regiões por onde pregaram e empreenderam seu trabalho catequético nas reduções. Com a finalidade de produzir um tratado médico, uma detalhada descrição a respeito da fauna, da flora e dos demais elementos que compunham o meio ambiente, ou simplesmente com a intenção de retratar as adversidades e os riscos pelos quais passavam, os jesuítas registraram em suas obras uma série de informações com tantos detalhes e esmero nas descrições, que só estudiosos poderiam ter realizado. Homens que procediam com os métodos científicos de sua época, que indicavam, inclusive, como descrever aquelas novas realidades que afrontavam. Porém, a escrita respondia a uma grade sobre o que se deveria escrever. Aspecto que, em certa medida, e mediante as correções que aprovariam o registro, não só condicionavam o autor, como também transformavam em dissonância com o resto da obra autoral, bem como os demais escritos jesuíticos, aqueles traços da escrita afetada.

Esta apreciação da natureza americana não era motivada pela curiosidade de mentes desocupadas - os jesuítas que produziram todo esse conhecimento tinham ciência de sua responsabilidade e seguiram métodos para a execução de suas obras. Mas a formulação de tal conjunto de saberes só foi possível por causa da ajuda de indígenas que, além de intérpretes, possuíam o domínio dos elementos que compunham o meio ambiente que habitavam. Grandes conhecedores das ervas, das plantas, dos costumes dos animais, dos perigos e benefícios que a natureza reservava, os índios ajudaram muito os missionários que se aplicaram nos estudos de biologia e na formulação de um catálogo de medicamentos naturais. Contudo, os nativos não ficaram reservados apenas à função de auxiliares: o conhecimento que possuíam tanto em relação à variedade de espécies, nomenclaturas, utilidades e formas de manipulação de substâncias, além de especificidades relativas tanto à fisiologia como ao comportamento dos animais, contribuiu para que os jesuítas ficassem atentos ao que os indígenas tinham a dizer. E foi justamente devido a esse interesse na perícia nativa, 
somado ao olhar investigativo dos jesuítas estudiosos, que se pode ter acesso a uma gama interessante de dados a respeito do saber indígena. Se os padres não tivessem percebido a potencialidade de informações contidas no que os índios tinham a dizer e os tivessem ignorado completamente, rebaixando-os à condição de selvagens indômitos e incapacitados para qualquer atividade intelectual, dificilmente tais considerações acerca do entendimento indígena seriam registradas por colonos ou autoridades administrativas.

Em geral, os jesuítas não negaram aos índios um conjunto de saberes que, no mínimo, Ihes guiavam nas atividades práticas do cotidiano - ainda que, para os ocidentais modernos, era improvável que os ameríndios pudessem desejar compreender o mundo que os envolvia a partir de um "pensamento desinteressado" (LÉVI-STRAUSS 1978, p. 30). Isto fica claro quando se observa que, no século XVIII, as discussões a respeito não só da condição dos nativos, como sobre a natureza americana avançavam para análises comparativas baseadas no determinismo biológico, como as ideias defendidas por GeorgesLouis Leclerc, o conde de Buffon, e Cornelius de Pauw. Buffon associou a fauna americana, ausente de animais de grande porte, e o clima excessivamente úmido ao fato de a América ser um continente novo e, por isso, imaturo, em que a vida, fosse ela animal, vegetal ou humana, estaria em seu estado bruto e selvagem. Pauw, partindo das conclusões de Buffon, debruçouse principalmente em analisar o nativo americano, que classificou como degenerado, fraco e malformado - fundamentalmente, justificou o jurista, devido às condições climáticas e ao ar insalubre, que impediam tanto o desenvolvimento dos animais e plantas, como dos humanos. "A ideia de imaturidade que Buffon atribuiu à natureza do Novo Mundo foi transformada por De Pauw em decadência e degenerescência" (FERES JúNIOR 2008, p. 15; cf. também LINDO 2012). De todos os críticos que se posicionaram contra essas teorias antiamericanistas, certamente os jesuítas que missionaram junto aos índios foram as vozes com maior embasamento para contrapor argumentos fundamentados a partir do conhecimento in situ: mesmo 
que a visão sobre a rudimentaridade dos índios não tenha se alterado estruturalmente, certamente o convívio direto com os nativos e com a natureza americana amenizou intransigências. O ímpeto investigativo dos missionários, somado à posição relativamente "imparcial e aberta dos jesuítas frente aos indígenas" (ANAGNOSTOU; FECHNER 2011, p. 190) permitiu que alguns deles refutassem estas teorias. Nesse sentido, os jesuítas "foram, em seus escritos, ativos refutadores das ideias antiamericanistas" (JUSTO 2011, p. 163) - como foi o caso do padre José Jolís.

Como tantos outros jesuítas em situação de exílio, Jolís escreveu suas memórias baseando-se nas experiências do convívio com os índios. Missionário que atuou principalmente entre grupos de etnia guaicuru, como os Toba, os Mataguayo e os Pilagá, até a expulsão da Ordem em 1767, é um exemplo contundente do impacto que a relação direta gerou nos missionários que estavam dispostos a conhecer o novo. Mais preocupado em decifrar a fauna e a flora do Chaco, Jolís escreveu seu livro em uma narrativa que oscila entre a descrição metódica e a preocupação em responder às teorias antiamericanistas - inclusive referindo-se diretamente a esses teóricos. Sua escrita assume a postura quase científica de apresentar detalhes dos usos e costumes dos indígenas frente aos elementos do ambiente em que viviam, pois tinha a intenção de apresentar os índios não como pessoas movidas pelo instinto selvagem em busca apenas da sobrevivência, mas como observadores atentos do seu mundo, admitindo serem peritos na manipulação de seu meio. Como um dos exemplos que oferece, Jolís cita a diversidade de espécies de papagaios que pôde presenciar, com grandes variações nas cores das penas e de seus tamanhos, sendo os índios responsáveis por essa diversidade já que "fazem a seu critério mudar as cores e embelezar com outros mais bonitos, que, perpetuando-se através da reprodução, tornam-se únicos e indeléveis". Atribui aos nativos um conhecimento experimental acerca do que o próprio jesuíta chama de ornitologia, demonstrando que ia além do funcionalismo prático - e, por isso, termina afirmando que 
"com isso, as raças e variedades vão aumentando, assim como as nações não civilizadas aumentaram as de cães, pombos e muitos outros quadrúpedes e aves ao praticarem o cruzamento mestiço" (JOLÍs 1789, p. 200-201).

A origem dessa diversidade era decorrente do trato e do conhecimento que possuíam e mantinham com as entidades e os seres do Chaco. A experiência resultante do convívio e da observação, somada a uma necessidade de conhecer - e não exclusivamente de um conhecer movido pela necessidade -, proporcionaram aos índios as faculdades cognitivas e instrumentais propícias para que se constituíssem como consumidores e fornecedores de recursos no ambiente em que viviam:

Para transformar uma erva silvestre em planta cultivada, uma besta selvagem em animal doméstico, para fazer aparecer em uma ou em outra propriedades alimentares ou tecnológicas que, em sua origem, estavam completamente ausentes ou apenas podiam ser suspeitadas; para fazer de uma argila instável prestes a esfarelar-se, a se pulverizar ou a rachar uma cerâmica sólida e vedada $[. .$.$] ; para elaborar técnicas, muitas vezes longas e$ complexas, que permitem cultivar sem terra ou sem água; para transformar grãos ou raízes tóxicas em alimentos ou ainda utilizar essa toxicidade para caça, a guerra ou o ritual, não duvidemos de que foi necessária uma atitude de espírito verdadeiramente científico, uma curiosidade assídua e sempre alerta, uma vontade de conhecer pelo prazer de conhecer, pois apenas uma pequena fração das observações e experiências (sobre as quais é preciso supor que tenham sido inspiradas antes e sobretudo pelo gosto do saber) podia fornecer resultados práticos e imediatamente utilizáveis (LÉVI-STRAUSS 1962, p. 30-31).

Os índios não só conheciam a dinâmica do ambiente em que viviam, como também eram agentes ativos e, em parte, responsáveis pela dinâmica da vida nesse meio. A atuação humana sobre o ambiente é geradora de uma importante contribuição para a existência da agrobiodiversidade, mesmo nos recantos mais isolados do mundo. Assim, "boa parte daquilo que parece mata primária é floresta há muito tempo 
manejada por indígenas" (CARNEIRO DA CUNHA 2009, p. 332). Entende-se a quantidade de plantas e a variedade de espécies que formavam o cenário da região chaquenha, em que, por exemplo, podia-se encontrar cerca de dezesseis tipos de milho diferenciados pela cor, "como o branco, amarelo, roxo, vermelho, azul turquesa, avermelhado e preto" (JOLÍs 1789, p. 91-92).

O olhar atento dos missionários preocupados com a coleta e catalogação de informações sobre os índios e a natureza não deixou de ignorar o fato de os nativos terem um conhecimento específico sobre a fauna e a flora, que ia além das necessidades de subsistência. Assim, em seus tratados científicos ou em suas memórias, os jesuítas chegavam a referenciar o saber indígena para fundamentar algumas informações sobre plantas medicinais ou usos de substâncias, dando crédito aos índios "sobre a localização e sobre as propriedades curativas das plantas nativas" (FLECK 2016, p. 68). Dessa forma, os missionários reconheciam a importância do conhecimento que os nativos possuíam, consultando-os frequentemente em suas investidas científicas e citando-os, muitas vezes, como suas fontes.

O padre Pedro Lozano reserva uma breve parte de sua Descripción Corográfica del Gran Chaco Gualamba para listar algumas ervas medicinais encontradas na região, reconhecendo a causa divina como responsável pela diversidade: "Como a falta de médicos e medicamentos é bastante significativa nesta parte da América, Deus Ihes forneceu uma farmácia natural em muitas plantas, cujo uso tem efeitos admiráveis" (LOZANO 1733, fl. 30). As substâncias naturais que o jesuíta descreve são todas eficazes contra venenos, mordidas e picadas de animais típicos do Chaco, cuja manipulação e uso são de domínio dos índios que conviviam diretamente com tais perigos e certamente ensinaram-lhe todo esse conhecimento - mas o missionário só acaba revelando a sua fonte, quando trata da yerba de víbora, remédio eficaz contra venenos de cobra, que só passou a ser usado 
pelos colonos quando um índio "muito cristão e caridoso divulgou sua virtude" (LOZANO 1733, fl. 31).

O padre jesuíta Martín Dobrizhoffer, um exímio conhecedor da organização social dos nativos, mais conformado com a perícia indígena, atesta que entre os Abipones, com quem conviveu como missionário por mais de uma década, os curandeiros "são especialistas conhecedores da utilidade de ervas medicinais que ali crescem em abundância incrível" (1784, t. 2, p. 250) e, um pouco mais adiante na sua narrativa, descreve o uso que os índios faziam da substância contida no chocalho da cauda das cascavéis para curar dores de dentes e outras doenças (DOBRIZHOFFER 1784 , t. 2, p. 257).

Apesar de uma menção como essa, o ponto central da narrativa de Dobrizhoffer encontra-se nas relações políticas que se manifestaram mediante um extenso e, por momentos, confuso período de guerras, que envolveu distintos grupos parentais e manteve as fronteiras chaquenhas instáveis chegando, inclusive, a colocar a vida do jesuíta em risco.

Em um momento particular da narração dos turbulentos acontecimentos, Dobrizhoffer expõe claramente possuir medo e, em uma escrita mais objetiva, passa a descrever os procedimentos que tomou para tentar salvar sua vida. A escrita afetada pelas intempéries da vida solitária, isolada e em constante alerta refletem, inclusive, o desejo de Dobrizhoffer de não estar em meio ao Chaco:

Falando francamente, me assusta não tanto a ameaça dos bárbaros, quanto o terror de meus companheiros. Pois, para não ficar sozinho e a pé naquela vastidão caso abandonassemme, mandei que preparassem o mais rápido dos meus cavalos, que seria o instrumento de minha segurança $[\ldots]$. Cansado do passeio de um dia inteiro, vencido pelo sono, dormi [...]. O extremo cansaço e a firme convicção de que os bárbaros não tentariam nada contra nós transportaram-me para um tempo e um lugar muito distantes (DOBRIZHOFFER 1784, t. 3, p. 219). 
Todo o esforço do missionário acaba fraquejando frente à indefinição que provoca o Outro, que, apesar de ser conhecido, não é previsível. Naquela ocasião, o sacerdote se encontra ante a disjuntiva de confiar em si mesmo, em seus companheiros ocasionais ou nas reações dos nativos. Mais adiante, e para resolver a questão sobre por que não foram atacados, faz menção ao fato de os indígenas estarem coletando mel nas imediações e secando couros de lontra.

Esta breve menção sobre a relação entre a organização social nativa e a escrita missionária é apenas um indicativo a respeito de onde e como analisar a presença da afetação na narrativa jesuítica. Acreditamos que possa ser encontrada em todas as expressões da vida reducional que geraram um contraste, um deslocamento da posição do jesuíta como sujeito que controla as relações sociais - controle que, certamente, só existia no papel. A função do jesuíta dentro da redução, na relação com os índios, acabava por estabelecer-se a partir das recusas dos convites para as bebedeiras e festas, além de não formar alianças matrimoniais com as mulheres.

Essas ações eram, em parte, as que faziam com que os índios observassem constantemente a atuação dos padres e que incidiam sobre o comportamento que o jesuíta registrava sobre a vida cotidiana dos nativos. Os conhecimentos que o jesuíta sistematizava pela escrita, sem dúvida, chamaram a atenção dos índios tanto como a negação jesuítica de não se deixar influenciar por algumas práticas nativas, como também alguns saberes médicos e suas implementações. Desse modo, o missionário, em sua experiência cotidiana, coletava uma série de informações, cujo uso não podia ser previsto em sua totalidade, gerando assim um "efeito etnográfico" a posteriori (STRATHERN 2014, p. 353-354). Sendo assim, durante o processo de reconectar os sentidos que aqueles eventos significavam em seu contexto e mobilizariam no meio no qual se deram a conhecer essas informações, o missionário se encontrava frente à imposição de voltar a tentar controlar os eventos e personagens com os quais havia interagido para que 
pudessem ser transmitidos por uma escrita que possuía normas claras e rígidas. É no marco dessa tensão que a afetação sofrida se integrava à escrita.

\section{Consideraçōes finais}

Si encuentras algo de bárbaro en mi discurso, desconózcalo el lector prudente, ya que el autor ha vivido tantos años entre las selvas y los bárbaros de América (DOBRIZHOFFER 1784, t. 3, p. 381)

É correta a premissa de que, quando os jesuítas escreviam sobre os indígenas, estavam descrevendo mais sobre si mesmos do que sobre os costumes e tradições dos nativos com quem conviveram, justamente por partirem de uma noção de "identidade cristã universal" como forma de compreender o "'outro'" (AGNOLIN 2016, p. 32). Dessa forma, não apenas criaram mecanismos de interpretação e adequação da alteridade estranha ao antigo "modelo evangélico mediterrâneo", como alcançaram "uma consciência mais profunda de si e do mundo", que "permitia superar a particularidade própria ou alheia" (AGNOLIN 2016, p. 31). O mesmo empreendimento missionário que estabelecia a convivência reducional direta como forma de conversão do selvagem em cristão foi o responsável por uma aproximação de entendimentos sobre a realidade que divergiam não apenas na ordem prática, mas, fundamentalmente, no que tangia a conceitos e lógicas. Daí o estranhamento causado na situação de convivência, em que ambos, jesuítas e indígenas, interagiam a partir do desconhecimento que tinham a respeito um do outro - o que, de maneira alguma, impedia que se avaliassem e julgassem-se a todo momento.

Assim, "as cartas eram espelhos de seu autor, dizendo muito mais do que ele pretendia deixar no rastro premeditado da escrita" (MORALES 2011, p. 36) - mas não só isso: os registros jesuíticos também demonstram um estado de relações entre missionários e indígenas em que os primeiros 
se afetaram diretamente com a atuação dos segundos. A presença do nativo, mesmo que esse fosse alvo da catequese e dos esforços de conversão ao cristianismo, mobilizou a forma com que os jesuítas detinham os eventos à sua volta e registravam suas impressões. A situação de contato e convívio direto resultou, empiricamente, em um vínculo presencial, não necessariamente de entendimento mútuo, mas que levou todos os personagens envolvidos (fossem jesuítas, caciques, funcionários dos cabildos, milicianos ou demais indígenas) a tornarem-se observadores, investigadores e negociadores das relações que estavam mobilizando.

No caso da Companhia de Jesus, entre os diversos membros da Ordem ligados entre si através de uma escrita institucionalizada, existiram, sem dúvida, sujeitos que detinham habilidades notórias para a construção de narrativas sobre a atuação missionária, as quais os diferenciavam de seus companheiros. Ainda que a escrita estivesse diretamente relacionada ao ofício jesuítico, incentivando todos os membros da Ordem como "um instrumento decisivo para o êxito da ação missionária" (PÉCORA 1999, p. 373), alguns jesuítas se destacaram pelo conteúdo intelectual de seus registros e o consequente alcance e influência que obtiveram por meio de suas cartas ou obras publicadas. Eram jesuítas cuja escrita expressava sua singularidade nas "aptidões e nas escolhas que fizeram, em seus temperamentos e na ousadia que demonstraram ter e, muito especialmente, no papel de mediadores culturais que desempenharam" (FLECK et al. 2014 , p. 26). A perícia na escrita não só se ponderava pela capacidade em descrever, mas também pelo discernimento que dispendiam ao registrar detalhes que, lidos por inimigos da Companhia de Jesus, pudessem ser usados para formular argumentos antijesuíticos.

A escrita dentro da Companhia de Jesus foi pensada, como apontamos, para uma melhor administração e controle das vontades pessoais dos sacerdotes espalhados pelo orbe, bem como para a leitura nos centros educacionais da Ordem como 
elemento pedagógico para instruir os futuros missionários a respeito dos indígenas do Novo Mundo e como deveriam lidar com as contingências que ameaçavam o sucesso do trabalho evangelizador. Dentro dessa função pedagógica, devemos incluir o aspecto nada insignificante, e pouco conhecido, da leitura que os noviços faziam de um esquema proto-etnológico, ainda que bastante simplificado, tendente a homogeneizar o espaço e os grupos nativos ao mesmo tempo em que reproduzia uma imagem de barbárie na qual os nativos eram bebedores inveterados, propensos a desobedecer seus caciques, de espírito inconstante e suscetíveis a acreditar em truques de seus feiticeiros. Consequentemente, essa escrita tendia a contradizer o poder catequético dos missionários: ainda que aparentemente haviam apreendido os nativos por meio da tinta e do papel, os indígenas continuavam incorrigíveis em seus ciclos de guerra os quais pareciam reproduzir-se, pelo menos para o missionário, sem uma causa clara e racional.

Como mencionamos, sabemos pouco sobre como essas descrições foram lidas nos Colégios e Universidades e menos ainda sobre como essas leituras afetaram a observação, a interpretação, a explicação e a narração que cada missionário construiu em seus escritos. $O$ evidente é que o peso performativo dos primeiros escritos é tão forte que podemos encontrar as mesmas figuras retóricas - guerras, borracheras, feitiçaria, danças e cantos desenfreados no quadro das práticas corporais quase orgíacas - em todas as descrições e histórias escritas pelos missionários.

Ao que parece, alguns missionários perceberam que o que acontecia em seu cotidiano tinha raízes que transcendiam a natureza inconstante dos nativos. Alguns trechos da documentação com as quais trabalhamos nos permitem vislumbrar essa questão, mas o peso normativo da escrita inaciana impediu dar um relato completo dos processos que estavam por trás daquilo que a Companhia de Jesus impediu de conhecer valendo-se da recorrência de uma escrita corrigida por aqueles que tiveram essa função dentro da Ordem. 
Em contrapartida, assim como os jesuítas se preocuparam em relatar sobre o conhecimento indígena a respeito da flora, inclusive assumindo a possibilidade de se utilizarem deste domínio, ou se empenharam em investigar as curas xamânicas a ponto de desvendarem procedimentos com uma lógica terapêutica inesperada, os índios que habitaram as reduções não deixaram de engajar-se nas causas promovidas pelos padres, nem deixaram de manter seus costumes autóctones. Em um artigo clássico, Eduardo Viveiros de Castro partiu justamente dessa "equação selvagem" - a "aceitação entusiástica mas altamente seletiva de um discurso totalizante e exclusivo, a recusa em seguir até o fim o curso desse discurso" - (1992, p. $187 ; 191)$, a fim de esclarecer que a narrativa colonial impressa em cartas, relatórios, memórias ou qualquer outro registro produzido sobre os indígenas é o ponto de encontro de dois eixos ontológicos: o modo de parecer dos nativos aos olhos dos agentes coloniais e o modo de ser dos indígenas, que foi interpretada como inconstante por missionários, administradores e colonos. Assim, tanto a presença indígena, como o convívio direto ocasionado pelo contexto das missões catequizadoras geraram registros muito específicos, identificados por Alcir Pécora como "mapas retóricos", em que os termos desta escrita são "reapropriados segundo a ocasião e aplicados segundo o caso" (2006, p. 13).

Identificar a escrita afetada significa muito mais que atentar para os problemas de adaptação/integração/aceitação que tiveram que enfrentar os sacerdotes. A escrita afetada possibilita identificar perspectivas sobre a vida cotidiana nas reduções, assim como, estimamos, é uma proposta para refletir sobre como aquele mundo americano foi repensado tendo em conta leitores europeus. A atuação missionária era um empreendimento que deveria ser conhecido a partir de ajustes às normas de publicação estabelecidas e que partia desde uma comunicação afetiva (FAVRET-SAADA 1990) com a Ordem e com os nativos que deram sentido à obediência jesuítica, que se traduzia por meio das reduções e dos escritos que se produziram sobre elas. 
AGNOLIN, Adone. Jesuítas e Selvagens: a negociação da fé no encontro catequético-ritual americano-tupi (Séculos XVI-XVII). São Paulo: Humanitas Editorial, 2007.

AGNOLIN, Adone. Catequese da língua e gramática ritual na conversão indígena: limites e espaço para o processo de conversão e negociação jesuítica e indígena na América portuguesa (sécs. XVI-XVII). In: FERNANDES, Eunícia Barros Barcelos (org.). A Companhia de Jesus e os índios. Curitiba: Editora Prismas, 2016. p. 23-49.

ANAGNOSTOU, Sabine; FECHNER, Fabian. Historia Natural y Farmacia misionera entre los jesuitas en el Paraguay. In: WILDE, Guillermo (ed.). Saberes de la conversión: jesuitas, indígenas e imperios coloniales en las fronteras de la cristiandad. Buenos Aires: SB, 2011. p. 175-190.

BARTHES, Roland. El Placer del Texto y Lección Inaugural de la cátedra de semiología literaria del Còllege de France. Buenos Aires: Siglo XXI, 2008 [1978].

CARGNEL, Josefina. La historiografía de la Compañía de Jesús. Pedro Lozano, su historiador. Tese (Doutorado em História). Facultad de Filosofía y Humanidades, Universidad Nacional de Córdoba, Argentina, 2015.

CARGNEL, Josefina; PAZ, Carlos D. Crónicas de la Barbarie. Categorías y formas de organización de la política nativa chaqueña, analizadas y narradas por la Compañía de Jesús. Páginas. Revista digital de la Escuela de Historia, ano 4, n. 7, 2012.

CARNEIRO DA CUNHA, Manuela. Cultura com Aspas. São Paulo: Cosac Naify, 2009. 
CASTELNAU-L'ESTOILE, Charlotte. Interações missionárias e matrimônios de índios em zonas de fronteiras (Maranhão, início do século XVII). Tempo, v. 19, n. 35, p. 65-82, 2013.

CERTEAU, Michel. A escrita da História. Rio de Janeiro: Forense Universitária, 2002 [1975].

DOBRIZHOFFER, Martín. Historia de los Abipones. Resistencia: Universidad Nacional del Nordeste, 3 tomos, 1967-1970 [1784].

EGIDO, Teófanes; BURRIEZA, Javier; REVUELTA, Manuel. Los jesuitas en España y en el mundo hispánico. Madri: Marcial Pons, 2004.

FAVRET-SAADA, Jeanne. Ser afetado. Cadernos de Campo, n. 13, p. 155-161, 2005 [1990].

FERES JÚNIOR, João. O conceito de América: conceito básico ou contra-conceito? Jahrbuch fur Geschichte Lateinamerikas, v. 45, p. 9-29, 2008. Disponível em: https://doi.org/10.7767/jbla.2008.45.1.9. Acesso em: 25 abr. 2018.

FLECK, Eliane Cristina Deckmann. Concepções e saberes distintos, encontros possíveis: uma reflexão sobre os papéis desempenhados pelos indígenas nas fontes jesuíticas (Província Jesuítica do Paraguai, séculos XVII e XVIII). In: SANTOS, Maria Cristina dos; FELIPPE, Guilherme Galhegos (orgs.). Protagonismo ameríndio de ontem e hoje. Jundiaí: Paco Editorial, 2016. p. 53-90.

FLECK, Eliane Cristina Deckmann; RODRIGUES, Luiz Fernando Medeiros; MARTINS, Maria Cristina Bohn. Enlaçar mundos: três jesuítas e duas trajetórias no Novo Mundo. São Leopoldo: Oikos; Editora Unisinos, 2014.

FURLONG, Guillermo, SJ. Joaquín Camaño, S. J. y su "Noticia del Gran Chaco" (1778). Buenos Aires: Librería del Plata, 1955. 
GINZBURG, Carlo. O fio e os rastros: verdadeiro, falso, fictício. São Paulo: Companhia das Letras, 2007.

HARTOG, François. O Espelho de Heródoto: ensaio sobre a representação do outro. Belo Horizonte: Ed. UFMG, 1999 [1980].

JOLÍS, José. Ensayo sobre la Historia Natural del Gran Chaco. Resistencia: UNNE/Facultad de HumanidadesInstituto de Historia, 1972 [1789].

JUANES, Benigno. La Elección Ignaciana por el Segundo y Tercer Tiempo. Centrum Ignatianum Spiritualitatis: Roma, 1980.

JUSTO, María de la Soledad. Paraguay y los debates jesuíticos sobre la inferioridad de la naturaleza americana. In: WILDE, Guillermo (ed.). Saberes de la conversión: jesuitas, indígenas e imperios coloniales en las fronteras de la cristiandad. Buenos Aires: SB, 2011. p. 155-174.

KELLY, José Antonio. Fractalidade e troca de perspectivas. Mana, v. 7, n. 2, p. 95-132, 2001. Disponível em: http:// dx.doi.org/10.1590/S0104-93132001000200004. Acesso em: 24 jan. 2018.

LARA, Lucas Ferreira de. A música instrumental: o padre Antônio Sepp, S. J., e as práticas musicais nas reduções jesuíticas (1691-1733). Dissertação (Mestrado em História Social). Departamento de História, Universidade de São Paulo, 2015.

LÉVI-STRAUSS, Claude. O Pensamento Selvagem. Campinas, Papirus, 1989 [1962].

LÉVI-STRAUSS, Claude. Mito e Significado. Lisboa: Edições 70, 1981 [1978]. 
LINDO, Luiz Antônio. A América dividida entre Gabriel Soares de Sousa e Cornelius de Pauw. Cadernos PROLAM/USP, v. 11 , n. 21 , p. 35-44, 2012. Disponível em: http://dx.doi. org/10.11606/issn.1676-6288.prolam.2012.82503. Acesso em: 17 jul. 2018.

LONDOÑO, Fernando Torres. Escrevendo cartas. Jesuítas, escrita e missão no século XVI. Revista Brasileira de História, v. 22, n. 43, p. 11-32, 2002.

LOZANO, Pedro, S.J. Descripción chorographica de Terreno Ríos, Arboles, y Animales de las dilatadísimas provincias del Gran Chaco, Gualamba, y de los Ritos y Costumbres de las innumerables naciones de barbaros e infieles que le habitan. Córdoba: Colegio de Asunción, 1733.

MARTÍNEZ, Fernando Betancour. Significación e Historia: el problema del límite en el documento histórico. Estudios de Historia Moderna y Contemporánea de México, n. 12, p. 59-78, 2001.

MILLONES FIGUEROA, Luís; LEDEZMA, Domingo. Introduccion: los jesuitas y lo conocimiento de la naturaleza americana. In: MILLONES FIGUEROA, Luís; LEDEZMA, Domingo. El saber de los jesuitas, historias naturales y el Nuevo Mundo. Frankfurt: Vervuert; Madrid: Iberoamericana, 2005, p. 9-26.

MORALES, Martín M. La respiración de ausentes. Itinerario por la escritura jesuítica. In: WILDE, Guillermo (Org.). Saberes de la conversión: jesuitas, indígenas e imperios coloniales en las fronteras de la cristiandad. Buenos Aires: SB, 2011, p. 31-59.

MÖRNER, Magnus. La Corona Española y los Foráneos en los Pueblos de Indios de América. Ediciones de Cultura Hispánica: Madrid, 1999. 
NEUMANN, Eduardo. Letra de índios. Cultura escrita, comunicação e memória indígena nas Reduções do Paraguai. São Bernardo do Campo/SP: Nhanduti Editora, 2015.

NEUMANN, Eduardo. "Ni V. E. ignora que no he tenido ociosa la pluma": A polémica produção escrita de um jesuíta durante o Tratado de Limites. Revista de Estudos de Cultura, n. 5, p. 35-48, 2016.

OLLERO, Héctor Sainz; OLLERO, Helios Sainz; CARDONA, Francisco Suárez; ONTAÑóN, Miguel Vázquez de Castro. José Sánchez Labrador y los naturalistas jesuitas del Río de la Plata. La aportación de los misioneros jesuitas del siglo XVIII a los estudios medioambientales en el Virreinato del Río de la Plata, a través de la obra de José Sánchez Labrador. Madri: MOPU, 1989.

PANAZZOLO, Lidiane Ferreira; MASSIMI, Marina. Categorias antropológicas nos Catálogos Trienais da Companhia de Jesus. IHS. Antiguos jesuitas en Iberoamérica, v. 3, n. 1, p. 21-45, 2015.

PAUCKE, Florián, S.J. Hacia Allá y Para Acá. Santa Fe: Ministerio de Innovación y Cultura de la Provincia de Santa Fe, 2010 [1767].

PAZ, Carlos D. "Pues nosotros somos capaces..." Reclamos indígenas en las fronteras abipón - santafesinas. Segunda mitad del siglo XVIII. Anuario IEHS, n. 22, p. 273-300, 2007.

PAZ, Carlos D. La Modernidad de los Bárbaros. Los abipones de San Jerónimo del Rey y sus relaciones sociales con las fronteras santafesinas del Chaco. História Unisinos, $v$. 13, n. 3, p. 253-264, 2009. Disponível em: http://dx.doi. org/10.4013/htu.2009.133.04. Acesso em: 06 mar. 2013.

PÉCORA, Alcir. Cartas à segunda escolástica. In: NOVAES, Adauto (org.). A Outra Margem do Ocidente. São Paulo: Minc-Funarte, Companhia das Letras, 1999, p. 373-414. 
PÉCORA, Alcir. Prefácio: occide et manduca. In: LUZ, Guilherme Amaral. Carne Humana. Canibalismo e retórica na América Portuguesa. Uberlândia: EDUFU, 2006. p. 11-19.

SAEGER, James S. The Chaco Mission Frontier: The guaycuruan experience. University of Arizona Press: Tucson, 2000.

SANTAMARÍA, Daniel. Chaco Gualamba: del monte salvaje al desierto ilustrado. Cuadernos del Duende: San Salvador de Jujuy, 2007.

SANTOS, Maria Cristina dos. Lições de Erovocá: estratégicas narrativas do "eu" a partir do "outro". Estudos IberoAmericanos, v. 42, n. 3, p. 1095-1167, 2016. Disponível em: http://dx.doi.org/10.15448/1980-864X.2016.3.24070. Acesso em: 26 jun. 2017.

STRATHERN, Marilyn. O Efeito Etnográfico e outros ensaios. São Paulo: CosacNaify, 2014.

VALDÉS, José García de Castro. Polanco. El humanismo de los jesuitas (1517-1576). Bilbao; Santander; Madrid: Mensajero; Sal Terrae; Universidad Pontificia Comillas, 2012.

VALLE, Ivonne del. Escribiendo desde los márgenes: colonialismo y jesuitas en el siglo XVIII. México: Siglo XXI, 2009.

VILAÇA, Aparecida. Conversão, predação e perspectiva. Mana, v. 14, n. 1, p. 173-204, 2008. Disponível em: http:// dx.doi.org/10.1590/S0104-93132008000100007. Acesso em: 20 dez. 2017.

VITAR, Beatriz. Guerra y Misiones en la Frontera Chaqueña del Tucumán (1700-1767). Consejo Superior de Investigaciones Científicas: Madrid, 1997. 
VIVEIROS DE CASTRO, Eduardo. O mármore e a murta: sobre a inconstância da alma selvagem. In: VIVEIROS DE CASTRO, Eduardo. A Inconstância da Alma Selvagem. São Paulo: Cosac Naify, [1992] 2002. p. 183-264.

WILDE, Guillermo. Introducción: trazos de alteridad. In: WILDE, Guillermo. Saberes de la conversión: jesuitas, indígenas e imperios coloniales en las fronteras de la cristiandad. Buenos Aires: SB, 2011. p. 15-27.

WRIGHT, Jonathan. Os jesuítas. Missões, mitos e histórias. Rio de Janeiro: Relume Dumará, 2006.

\section{AGRADECIMENTOS E INFORMAÇŌES}

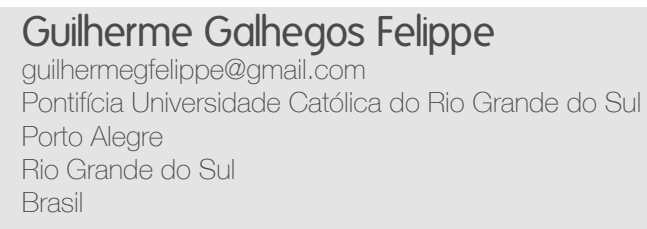

O presente trabalho foi realizado com apoio da Coordenação de Aperfeiçoamento de Pessoal Nível Superior - Brasil (CAPES) - Código de Financiamento 001. 